\title{
PRECARIZAÇÃO E FRAGMENTAÇÃO DO TRABALHO NA ESTRATÉGIA SAÚDE DA FAMÍLIA: IMPACTOS EM SANTA MARIA (RS)
}

\author{
PRECARIZATION AND FRAGMENTATION OF WORK IN THE FAMILY HEALTH STRATEGY: IMPACTS IN \\ SANTA MARIA (RS)
}

PRECARIZACIÓN Y FRAGMENTACIÓN DEL TRABAJO EN LA ESTRATEGIA SALUD DE LA FAMILIA: IMPACTOS EN SANTA MARÍA (RS)

\author{
Maria Denise Schimith ${ }^{1}$ \\ Ana Cristina Passarella Brêtas ${ }^{2}$ \\ Bruna Sodré Simon ${ }^{3}$ \\ Dyan Jamilles Teixeira Brum ${ }^{4}$
}

Resumo O estudo teve por meta compreender o processo de implantação e acompanhamento da Estratégia Saúde da Família em um município do Rio Grande do Sul, utilizando como metodologia a pesquisa qualitativa. Foram entrevistados 16 gestores e analisadas fontes documentais no período de agosto de 2011 a maio de 2012. O material foi submetido à proposta operativa de análise. Verificou-se que a primeira gestão da Estratégia desencadeou um processo efervescente para transformar uma realidade considerada fragmentada e insuficiente, tendo optado por terceirização na contratação dos trabalhadores, participação da comunidade e educação permanente. A segunda gestão optou por fortalecer as unidades de pronto atendimento, sem a participação do controle social. Apareceram como fragilidades da Estratégia a gestão do trabalho e as escolhas da gestão municipal. A reestruturação da atenção básica, objetivo da Estratégia, foi postergada. Como conclusão, identificou-se a complexidade de se fazer gestão municipal do Sistema Único de Saúde e sedimentar a atenção básica como porta preferencial dos cidadãos.

Palavras-chave gestão em saúde; recursos humanos em saúde; Estratégia Saúde da Família; Sistema Único de Saúde.

\author{
Gabriela Fávero Alberti ${ }^{5}$ \\ Maria de Lourdes Denardin Bidó ${ }^{6}$ \\ Taís Falcão Gomes ${ }^{7}$
}

Abstract The study aimed to understand the Family Health Strategy process implementation and monitoring at a municipality in the state of Rio Grande do Sul, Brazil, using as qualitative research methodology. Sixteen managers were interviewed and documentary sources analyzed in the period ranging from August 2011 to May 2012. The material was submitted to the operative analysis proposal. It was noted that the first management team of the strategy triggered an effervescent process of transformation of a reality considered as fragmented and insufficient, having opted for outsourcing in worker hiring, for community participation, and for permanent education. The second management team chose to strengthen the emergency units, with no participation of social control. Work management and the municipal management's choices were Strategy weaknesses. The restructuring of primary care, which the Strategy aimed at achieving, was postponed. In conclusion, the study showed the complexity of undertaking the municipal management of the Unified Health System and of sedimenting primary care as the citizens' preferred port.

Keywords health management; health human resources; Family Health Strategy; Unified Health System. 


\section{Introdução}

As transformações aceleradas no mundo do trabalho nos últimos anos têm provocado mudanças importantes no trabalho em saúde, especialmente em relação aos processos produtivos, ao trabalhador e às condições de trabalho. O presente estudo foi motivado pela experiência em atividades de ensino, pesquisa e extensão com a graduação e a residência multiprofissional nas unidades de saúde da família (USFs) do município de Santa Maria, no Rio Grande do Sul, o que provocou análises crítico-reflexivas sobre o processo saúde da família e permitiu a vivência de momentos diversos e marcantes. É indispensável o cuidado observado à especificidade dessa trajetória ao se desenvolverem pesquisas relacionadas a esse ponto da atenção à saúde.

Sabe-se que todo brasileiro tem direito à saúde, com respaldo na Constituição Federal de 1988, por meio do Sistema Único de Saúde (SUS), regulamentado pela lei n. 8.080/90. O SUS consiste em uma conquista social decorrente do Movimento de Reforma Sanitária, que trouxe avanços à saúde pública brasileira, especificamente no âmbito de sua organização.

É importante salientar que a atenção básica (AB) é um dos seus eixos estruturantes e introduz um movimento de repensar o sistema público, a partir de um ponto ordenador da rede de saúde caracterizado por acesso, resolutividade e acolhimento. Ele tem o objetivo de desenvolver a atenção integral e impactar o perfil de saúde e autonomia dos sujeitos, bem como os determinantes e condicionantes de saúde da população. Entende-se que a Política Nacional de Atenção Básica (PNAB), regulamentada pela portaria n. 2.488/2011, prevê sua capilaridade e proximidade com a vida das pessoas (Brasil, 2011a).

Desde a conquista do SUS até os tempos atuais, a $\mathrm{AB}$ passou por algumas interpretações diferenciadas. Evoluiu da ideia de atenção seletiva (programa destinado a populações pobres) e nível primário de atenção (organização e funcionamento como porta de entrada) para a estratégia de organização do sistema de atenção à saúde. Ela contempla a proposta de apropriar, recombinar e reordenar os recursos do sistema condizentes com a necessidade e a demanda da população (Mendes, 2012).

Dentre os fundamentos e diretrizes da $\mathrm{AB}$ pode-se elencar o território adscrito, o acesso universal, o desenvolvimento de vínculo e responsabilização e o estímulo à participação dos usuários (Brasil, 201 la). Esse cenário é a instância dos serviços de saúde que oferta a entrada no sistema, de maneira a direcionar o trabalho dos demais níveis de atenção, a fim de maximizar a saúde e o bem-estar da comunidade (Starfield, 2002). A saúde da família, criada em 1994, é a principal estratégia de reorganização do modelo de atenção à saúde no país; propõe-se a atuar sobre os determinantes sociais e 
reflete uma nova tendência de valorização da família na agenda das políticas públicas brasileiras (Mendes, 2012).

É preciso considerar que experiências de modelos de cuidados primários anteriores foram importantes e alguns deles ainda continuam vigentes no país, pois representam alternativas bem-sucedidas de ofertar uma $\mathrm{AB}$ com qualidade. Como exemplo, podem ser citados a Ação Programática em Saúde em São Paulo, SP (década de 1970); o modelo Em Defesa da Vida, desenvolvido no final da década de 80 em Campinas (SP); a Medicina Geral e Comunitária, impulsionada pelas residências médicas em Porto Alegre, RS (1983); o Programa Agentes Comunitários de Saúde (Pacs), em 1991; o Programa Médico de Família, em Niterói (RJ), em 1992; e o Programa Saúde da Família (PSF), implementado a partir de 1994 e atualmente denominado Estratégia Saúde da Família (ESF) (Mendes, 2012).

Uma das diretrizes organizacionais do SUS, a descentralização, constitui-se como uma das principais estratégias para auxiliar e melhorar a administração pública. Essa estratégia visa compartilhar as responsabilidades referentes à gestão em saúde entre União, estados e municípios da federação e reforça o papel de cada esfera na execução das ações de saúde. Tal processo refere-se à descentralização dos serviços de saúde e representa um dos princípios organizativos do SUS. Nesse sentindo, um dos avanços mais expressivos ocorreu com o processo de municipalização em que foi realizada a implementação da AB e, por sua vez, da ESF (Souza et al., 2011). Todavia, vale ressaltar que se destacam, entre os desafios atuais da AB e da ESF, o recrutamento, provimento e fixação de profissionais e a capacidade de gestão/coordenação do cuidado, além dos quesitos relativos ao acesso e acolhimento, à efetividade e resolutividade de suas práticas e legitimidade social (Brasil, 2011b).

É interessante destacar que a ESF apresentou um processo de expansão caracterizado por duas fases: a primeira, no período de 1994 a 1998, quando o programa passou de uma cobertura de $0,8 \%$ da população brasileira para 7\% (10.636.350 habitantes cobertos); e a segunda, de 1998 a 2000, cujo resultado final visou atender $22 \%$ do total de brasileiros, ou seja, 29.683.800 pessoas (Brasil, 2002). Sabe-se que o que diferencia consideravelmente uma fase da outra é a distribuição por regiões e porte de municípios, pois na primeira fase o programa estava circunscrito aos pequenos e médios municípios, principalmente da região Nordeste; e na segunda, a expansão ocorreu nas médias e grandes cidades das regiões Sudeste e Sul.

Atualmente, estima-se que $58,37 \%$ do espaço territorial brasileiro esteja coberto pela ESF. Essa porcentagem representa 109.341.094 brasileiros. Segundo dados do Ministério da Saúde (MS), a abrangência da cobertura foi de 4.664 municípios, em 2004, para 5.213 contemplados até julho de 2014. No mesmo período, somavam-se 34.216 equipes de saúde da família no país (Brasil, 2014). 
No estado do Rio Grande do Sul, em dezembro de 2013 existiam 433 municípios com ESF (1.417 equipes), cuja cobertura populacional compreendia 42,08\% (Brasil, 2014). O município pesquisado aderiu à ESF em 2004, por meio do Projeto de Expansão e Consolidação da ESF (Proesf). Com esse projeto, o ministério objetivou apoiar financeiramente a expansão da cobertura, a consolidação e a qualificação da ESF nos municípios brasileiros com população acima de 100 mil habitantes (Brasil, 2011c).

A obtenção desses dados permitiu inferir que há uma expansão progressiva e com ritmos diferenciados dependendo de cada região do país. É importante observar que a mudança causada por essa reorganização nos serviços de saúde pode ter influência direta nos indicadores da $\mathrm{AB}$ e, consequentemente, de vida da população.

O município pesquisado possui pouco mais de 260 mil habitantes. Em 2004, quando aderiu ao Proesf, a cobertura de ESF atingia 51.750 habitantes com 15 equipes de ESF, com o percentual de cobertura de 20,32\%. Em 2013, 55.200 pessoas estavam assistidas por 16 equipes, com um percentual de cobertura de 20,94\% (Brasil, 2014). Destaca-se que, no município estudado, a expansão da cobertura da ESF não ocorreu conforme planejado e aprovado pelo controle social, diferentemente da realidade brasileira, o que justificou a realização da pesquisa aqui apresentada.

Por conseguinte, a questão que norteou a pesquisa foi: como ocorreu o processo de implantação e acompanhamento da ESF em Santa Maria? Definiu-se como objetivo geral deste estudo compreender, na ótica dos gestores da atenção básica, o processo de implantação e acompanhamento da ESF nesse município do Rio Grande do Sul. E, como objetivo específico, procurou-se analisar, na perspectiva dos gestores, a implicação das escolhas da gestão na implementação da ESF.

\section{Caminho metodológico: abordagem qualitativa baseada no referencial teórico-analítico dialético}

Coerente com o trabalho descrito até aqui, a pesquisa ${ }^{8}$ se caracterizou por ser exploratória, de abordagem qualitativa, analisada com base no referencial teórico-analítico dialético (Minayo, 2013). Os depoimentos dos gestores envolvidos no processo de implantação e acompanhamento da ESF foram situados no tempo político de cada um dos governos municipais; consideraram a visão de mundo por meio das experiências dos participantes que, ao discorrer sobre os acontecimentos, revelaram a "prática social empírica dos indivíduos em sociedade" (Minayo, 2013, p. 108).

Durante o percurso metodológico, é essencial que o objeto de pesquisa e o método se relacionem dialeticamente e articulem a teoria com a realidade 
estudada (Minayo, 2013). Assim, nos depoimentos dos gestores revelou-se o seu entendimento acerca da organização do SUS, que influenciou nas escolhas da gestão e nas importantes mudanças ocorridas no período de implantação e implementação da ESF.

Dentre todos os envolvidos no processo de implantação - conselheiros, usuários, trabalhadores e gestores -, optou-se intencionalmente pelos últimos. A coleta de dados foi realizada por meio de entrevistas com gestores que compuseram as gestões 2004-2008 e 2009-2012. Utilizaram-se também fontes documentais - o período de coleta foi de agosto de 2011 a maio de 2012.

É preciso considerar que as entrevistas continham um roteiro formado por duas partes: a primeira com tópicos de identificação, e a segunda com temas abertos. Foram gravadas, transcritas na íntegra e, posteriormente, devolvidas aos entrevistados para conferência, respeitando suas correções. As pessoas entrevistadas foram escolhidas intencionalmente por indicação da rede de relações, que consiste em um processo no qual "cada informante remete o pesquisador a outros membros da sua rede para investigações subsequentes", até o momento em que o objetivo do estudo é atendido (Victora, Knauth e Hassen, 2000, p. 69). As entrevistas tiveram início com a secretária municipal de Saúde que estava à frente da pasta no momento da implantação da ESF. O processo da rede de relações foi formado com a indagação: qual gestor municipal que acompanhou a construção da ESF pode ser entrevistado? Entrevistaram-se 16 gestores.

Os documentos analisados foram resoluções e atas do Conselho Municipal de Saúde (CMS) e também documentos recebidos e expedidos por este órgão acerca da ESF, principalmente os que envolviam processos judiciais. A busca por informações pertinentes à implantação e ao acompanhamento da ESF guiou a análise dos documentos.

Compreendeu-se então que, no processo da análise, os dados da pesquisa foram interpretados utilizando a proposta operativa de Minayo (2013). Ao seguir suas etapas, foi possível construir uma versão da história do processo de implantação da ESF no município. Na perspectiva dialética, segundo a autora, faz-se necessária uma atitude crítica, não limitada a apenas interpretar, mas também considerando as relações sociais dinâmicas, antagônicas e contraditórias que ocorrem durante o processo (Minayo, 2013).

Por se tratar de uma pesquisa que envolve seres humanos, as normativas éticas e científicas pautadas na resolução n. 196/96 do Conselho Nacional de Saúde foram respeitadas (Brasil, 1996). Seguindo os princípios éticos, esta pesquisa foi aprovada pela gestão da Secretaria Municipal de Saúde (SMS) e pelo CMS do município. Em seguida, foi aprovada pelo Comitê de Ética da Universidade Federal de Santa Maria, sob o Certificado de Apresentação para Apreciação Ética (CAEE) n. 23081.007707/2011-51. Após o 
aceite, disponibilizou-se aos sujeitos pesquisados o termo de consentimento livre e esclarecido e também se ofereceu aos participantes a possibilidade de escolha de seu codinome, devidamente respeitada. Aos entrevistados que delegaram essa tarefa às pesquisadoras, foram atribuídos nomes próprios fictícios. Assim, indicou-se o nome fictício seguido da indicação do período da gestão de que participou.

\section{Interpretação e categorização resultantes da análise dialética}

\section{Caracterização dos participantes}

Entre os gestores entrevistados, 13 foram mulheres e três homens. Quanto à formação, nove eram enfermeiros, dois dentistas e dois fisioterapeutas, um psicólogo, um cientista social e um graduando em psicologia. Com exceção de um dos entrevistados, os demais sujeitos tinham pós-graduação, entre eles nove com mestrado e um com doutorado. As especializações eram, em sua maioria, sobre gestão em saúde pública e coletiva com ênfase na humanização. Esses participantes ocuparam os mais diferentes cargos na gestão; eram atores que em diferentes momentos exerceram funções também diferenciadas, ora gestores, ora trabalhadores de $\mathrm{AB}$ ou ESF, ora docentes de universidades. Em alguns casos, o mesmo profissional entrevistado exerceu um cargo na gestão e na equipe, em governos diferentes, o que permitiu a abordagem do tema por diversos ângulos, de modo a refletir a realidade dos fatos e possibilitar a triangulação dos dados.

\section{'O SUS na vida das pessoas': a implementação da ESF}

A concepção dos gestores que implantaram a ESF em 2004 no município estudado revelou que a $\mathrm{AB}$ desenvolvia uma assistência restrita, fragmentada. Essa concepção determinou e desencadeou um processo efervescente de fazer o novo e transformar essa realidade. Tal motivação permeou a construção inicial da ESF pelos gestores, refletindo e influenciando a forma de atuação das equipes.

\footnotetext{
Tu pensares os vazios assistenciais, a localização de uma unidade de saúde com uma delimitação geográfica de responsabilidade, com pessoas e com habitações que eram da sua responsabilidade, com uma lógica mais coerente de presença do SUS na vida das pessoas (Catina, $1^{\text {a }}$ gestão).
}

Foi assim que a Estratégia começou, com uma participação muito grande do controle social e das associações comunitárias, não só do Conselho de Saúde, mas de 
todos os movimentos sociais daquelas comunidades onde iriam ser implantadas as unidades de saúde da família (Dulce, $1^{\text {a }}$ gestão).

Constatou-se que a gestão municipal fez a opção de implantar a ESF com a participação da população, e assim pôde estabelecer uma coerência com as decisões políticas da proposta nacional. A ESF consistiu na aposta nacional de convergir com as diretrizes do SUS e o preceito constitucional de saúde como um direito. Nesse período, numerosas iniciativas se fizeram presentes no país, com o propósito de contribuir para a reorganização do modelo de atenção à saúde. Cite-se como exemplo a Política Nacional de Humanização (PNH) de 2004, caracterizada como uma política transversal que perpassou o conjunto de princípios e modos de operar os serviços de saúde e as relações profissional-usuário. Acrescente-se o Pacto pela Saúde, de 2006, que se referiu a um conjunto de compromissos sanitários assumidos pelos gestores do SUS (Brasil, 2004a, 2004b, 2006).

Nesse sentido, a implantação foi motivada por uma demanda social e construída com a participação de vários segmentos da sociedade. Do mesmo modo como os envolvidos estavam coerentes com a ideologia partidária do governo municipal, a proposta de implementação da ESF era reconhecida por quem não compartilhava da mesma ideologia.

Final de 2002 (...) a primeira vez que chegou essa discussão da ESF (...) foi uma demanda vinda do conselho, não foi da gestão. (...) como era uma administração popular, ela tinha na sua concepção a escuta da população. Foram mobilizadas nos bairros várias reuniões com a proposta de discutir a ESF (...) (Esmeralda, $1^{a}$ gestão).

Interessante reiterar que a participação popular na gestão da saúde é um preceito constitucional que deve ser estimulado pelos governantes, de modo a assegurar o comprometimento dos gestores públicos com a implementação de ações, programas e demais projetos referentes à saúde. Com isso, o papel do controle social na gestão do SUS está pautado na responsabilização e vigilância - e também na ideia de compromisso e efetividade com o bem comum (Rolim, Cruz e Sampaio, 2013).

As equipes, nessa gestão, foram contratadas mediante processo seletivo por meio de currículo e entrevista coletiva, para facilitar a contratação de pessoas com perfil adequado para a atuação em conformidade com a proposta da ESF. O vínculo empregatício foi estabelecido via consórcio intermunicipal, por orientação do próprio Ministério da Saúde. No início, a primeira gestão utilizou-se da educação permanente em saúde (EPS) para envolver os profissionais em questões estruturais da proposta de implantação, como a territorialização. As próprias equipes conheceram os territórios e fizeram os 
desenhos com a intenção de suprir os vazios assistenciais. O envolvimento dos trabalhadores de saúde foi reconhecido por todos. Associou-se tal reconhecimento ao modo de fazer gestão, pautado na corresponsabilização e na definição do projeto.

(...) a mudança da lógica do jeito de fazer (...) que fosse diferente e as equipes estavam mobilizadas, e isso fez com que as pessoas se envolvessem e se apaixonassem por aquele trabalho, tanto que a gente teve melhorias nos indicadores (Dulce, $1^{\text {a }}$ gestão).

A gente foi por unidade, sempre ia uma equipe da secretaria, fazia reunião nas associações comunitárias, se discutia, se abria para a comunidade fazer todas as perguntas, todas as dúvidas que eles tivessem. Foram definidos com a comunidade como eles queriam que fosse o atendimento, o horário de atendimento, se ia fechar ao meio-dia, se não ia fechar, enfim, a comunidade participou de tudo, bem participativa (Ametista, $1^{\mathrm{a}}$ gestão).

Como dito, esse movimento da gestão municipal promoveu um envolvimento tanto da comunidade quanto dos trabalhadores na implantação da ESF. Nesse período, houve a implantação da Política Nacional de Educação Permanente em Saúde (portaria GM/MS n. 198, de fevereiro de 2004, substituída pela portaria GM/MS n. 1.996, de agosto de 2007) (Brasil, 2007). A política trouxe o desafio de descentralizar a gestão da EPS na saúde. É importante salientar que a gestão colegiada deveria ser priorizada, de modo a provocar a superação da formação verticalmente imposta, possibilitando o protagonismo dos diferentes atores envolvidos na formação dos trabalhadores de saúde (Macêdo, Albuquerque e Medeiros, 2014).

Nesse sentido, a EPS previa o aperfeiçoamento cotidiano, que deve ser técnico, social, crítico, ativo e político. Representava ainda uma inovação com impactos na qualidade dos serviços de saúde, pois incidiam "sobre o seu cotidiano os processos de trabalho, as relações entre os trabalhadores das equipes que prestam os serviços, e deles com os usuários" (Franco, Chagas e Franco, 2012, p. 46). Todavia, investir em EPS com trabalhadores sem concurso público, com contratos temporários, acabaria por postergar o objetivo de reordenação da $\mathrm{AB}$.

\section{'E isso aí dá um baque na saúde’: o vínculo empregatício dos trabalhadores}

Outra etapa importante foi a que abrangeu o período de 2006 até o final de 2008. Esse ciclo foi determinante, na medida em que assinalou mudanças significativas relativas ao vínculo empregatício dos trabalhadores de saúde. 
Nos últimos dois anos da primeira gestão (2007-2008) da ESF, a questão trabalhista determinou um desinvestimento, tanto na gestão quanto nos trabalhadores. E o concurso público para as equipes, com exceção dos agentes comunitários de saúde (ACSs), não foi realizado. Esse resultado convergiu para o encontrado na região Nordeste, na qual a desprecarização do trabalho foi apontada como desafio (Rocha et al., 2008).

Tais fatos ocorreram na contramão da portaria n. 626/GM, de abril de 2004 (Brasil, 2004a), que elaborou as diretrizes do Plano de Carreira, Cargos e Salários no âmbito do SUS. Essa portaria apontou para a necessidade de se valorizarem os trabalhadores do SUS e de se retomarem suas identidades organizacionais. Dessa forma, a desestruturação dos planos de cargos e carreiras não se restringiu apenas a essa realidade, mas abrangeu todo o território nacional (Brasil, 2006).

Ademais, os desafios identificados para a gestão municipal da ESF foram fatores que implicavam a governabilidade da saúde. Destacaram-se, entre eles, o reconhecimento do controle social, a mobilização dos trabalhadores de saúde na defesa do SUS, uma proposta concreta para a pasta da saúde no município e a construção permanente da Rede de Atenção à Saúde (RAS).

Em 2007, a gestão municipal iniciou uma caminhada para a construção de um concurso público específico para a ESF, mas antes tinha que pensar como iria pagar todas as demissões impostas. (...) já não havia mais previsão orçamentária, então somente em 2008 é que deveriam iniciar as demissões escalonadas, e foi o que aconteceu. Neste período o projeto de lei estava construído há quase um ano e descansava na mesa da procuradora da Prefeitura. Nos dias de votação na Câmara Municipal, fomos com a comunidade para pressionar a sua aprovação. A lei foi promulgada em 2 de maio de 2008, lei municipal n. 5.110 (Mandacaru, $1^{a}$ gestão).

Além disso, o governo municipal, que teria eleição em 2008, deveria ter se apressado para a realização de concurso público, mas houve somente para os ACSs. Tal escolha de governo, dita por muitos dos gestores entrevistados como falta de vontade política, implicou consequências não somente para a ESF, mas principalmente para a população atendida.

Dessa maneira, com os contratos emergenciais, iniciava-se um período que, como o nome diz, deveria ser curto, emergente, mas perdurou por três anos (meados de 2008 até o início de 2011). A rotatividade de pessoal nas equipes foi explicada pela troca de governo e pela defesa do trabalhador efetuada pelo Termo de Ajuste de Conduta (TAC) imposto pelo Ministério Público do Trabalho (MPT). A eleição aconteceu em 2008; houve troca de partido político na condução do município, e a continuidade que deveria haver não aconteceu. 
O governo anterior assinou o TAC e saiu. (...) nós assumimos com o TAC em andamento e tivemos que demitir 162 pessoas, entre médicos, enfermeiros, agentes comunitários. Só agentes comunitários de saúde foram 120 (...) demitidos. E isso aí dá um baque na saúde que até hoje, recém [o município] está começando a melhorar desde aquela época (...) houve uma seleção por contrato emergencial (...) depois foi prorrogada por mais tempo. Quando venceu, nós estávamos naquela discussão com a promotoria e o Ministério do Trabalho se iria ter concurso público ou não para a Estratégia (Cíntia, $2^{\mathrm{a}}$ gestão).

Em julho de 2009, ao se realizar novo contrato emergencial, este se deu sem a participação do CMS, e até então não houve concurso público. A continuidade, portanto, não ocorreu. Assim, a gestora deixou explícito que precisou iniciar o processo todo novamente, e o CMS foi o protagonista na pressão para que o concurso fosse efetivado.

Há uma carta denúncia de março de 2010 do CMS ao Departamento Nacional de Auditoria do SUS (Denasus) que descreve esse processo. A carta informa que em 2010 os trabalhadores permaneciam terceirizados, fato considerado irregular pelo MPT, pois ele determina concurso público para admissão dos trabalhadores no regime estatutário durante o prazo das demissões.

Em 2011, o CMS não aprovou o relatório de gestão da SMS do primeiro semestre de 2010 em virtude, entre outras demandas, da não realização de concurso público para os profissionais da ESF. A ata da audiência pública com o MPT, em 13 de outubro de 2010, revelou a recomendação da imediata suspensão do processo licitatório e a necessidade de ser firmada pelo prefeito do município a realização de concurso público da área da saúde, com nomeação dos profissionais.

O estudo aqui apresentado procurou apontar quão expressiva era a relação de vínculos empregatícios precários ou por regime temporário para se alcançar a efetividade da proposta da saúde da família. Dessa forma, fazia-se necessário investir na estabilidade do profissional no serviço de saúde, bem como na legalidade dos contratos de trabalho, para proporcionar segurança e condições dignas ao exercício das atribuições profissionais (Fernandes et al., 2012).

Além disso, conforme salientam Medeiros e colaboradores (2010), a instabilidade dos profissionais induz a uma alta rotatividade na equipe de saúde, cuja motivação para trabalhar no serviço público está condicionada a diferentes fatores, como o vínculo concreto, o estilo de gestão, a relação política entre profissional e gestor municipal e a realização profissional no âmbito das políticas públicas. Os autores indicam a realização do concurso público e a existência de um plano de cargos e salários como estratégias para a desprecarização dos vínculos trabalhistas e a melhoria da qualidade no trabalho prestado pelos trabalhadores. 


\section{‘O gás inteiro é no pronto atendimento’: prioridades da nova gestão municipal}

Os entrevistados que estavam na gestão quando o governo municipal de 2009 assumiu relataram notória priorização de investimentos em urgência/emergência. Os gestores justificaram que o acompanhamento nos prontos atendimentos (PAs) do município não estava correspondendo às necessidades da população.

(...) nós tivemos outro eixo que foi prioritário e proporcionou uma inversão do modelo que a gente pretendia, que é a urgência e emergência, uma demanda muito forte que o governo teve que atacar primeiramente (...) nós temos em torno de dez mil atendimentos mensais [no PA]. Agora o prefeito conseguiu uma UPA [unidade de pronto atendimento], vai melhorar. Com a vinda do Samu [Serviço de Atendimento Móvel de Urgência], aumentou muito a demanda do PA (...) (Sérgio, $2^{\mathrm{a}}$ gestão).

A gente não consegue trabalhar, porque o quadro da doença está tão imposto, está tão forte a doença, que está muito difícil de a gente trabalhar promoção e convencer que a promoção tem que caminhar junto. O fortalecimento é igual. O que me empenha para o quadro agudo, eu tenho que me empenhar para promoção (...). E não está claro (...) nem para os profissionais que trabalham! (Borboleta, $2^{\mathrm{a}}$ gestão).

O gás inteiro é no pronto atendimento municipal. A ideia é colocar tantos cardiologistas, é colocar especialidade X. Então uma coisa é o discurso e uma coisa é a prática. Não estou fazendo uma crítica vazia, (...) a gestão desprovida de conhecimento (Luísa, $1^{\mathrm{a}}$ e $2^{\mathrm{a}}$ gestões).

Notou-se que houve períodos em que os atendimentos na ESF aconteciam de maneira muito fragilizada, sem vínculo, sem responsabilização e com ACSs sem referência. Novamente, esse fato acarretou consequências que ainda repercutiam nas equipes. Ainda permitiu dizer que aderir à ESF não significava essencialmente mudança de paradigma, pois essa transformação iria além da adequação à política, porque deveria incorporar elementos como o planejamento, o acolhimento, a escuta e a oferta de resposta resolutiva para os problemas de saúde da população, a responsabilidade e a integralidade do cuidado (Brasil, 201 la).

Outro desafio encontrado referiu-se à falta de continuidade entre as gestões na política municipal. Nesse contexto, os gestores entrevistados relataram a visível fragilidade do acompanhamento da gestão, que apresentava dificuldades em responder aos anseios das equipes. Assim, pôde-se pensar que talvez não houvesse empenho em dar continuidade a essa proposta. 
Eu vi e vivi duas gestões (...), uma gestão que era, sim, partidária, mas que tinha uma clareza conceitual e de conhecimento de causa; e vivi outra gestão extremamente partidária e que não tinha conhecimento de causa (Luísa, $1^{\mathrm{a}}$ e $2^{\mathrm{a}}$ gestões).

(...) acho muito triste que a gente tenha perdido em tão pouco tempo. Dois anos a gente perdeu tudo que tinha ali, não tem mais nada, na atenção básica (...) vários meses ficaram com ACS atendendo no posto, mais ninguém, médico voluntário, enfermeiro voluntário, atendendo (Andreia, $1^{\mathrm{a}}$ e $2^{\mathrm{a}}$ gestões).

Vale lembrar que, no período em que a segunda gestão investiu em atendimento de emergência e urgência, em 2006 foi sancionada a portaria n. 399 (Brasil, 2006). Ela trouxe ações referentes ao Pacto pela Saúde e à consolidação do SUS. Três diferentes compromissos foram ressaltados, por meio do Pacto pela Vida, do Pacto em Defesa do SUS e do Pacto de Gestão do SUS. Dessa maneira, firmaram-se compromissos e responsabilidades que tinham como foco proporcionar a melhor efetivação do sistema público de saúde.

É importante considerar que o gestor de saúde é a autoridade sanitária correspondente a determinada esfera de governo - na situação em questão, a esfera municipal. Para tanto, está o gestor municipal em um cargo administrativo que requer competências técnicas e políticas. Ele tem responsabilidades por um específico projeto de governo, bem como por seguir as políticas de saúde pautadas no âmbito nacional convergentes com o sistema de saúde - compreendidas as políticas de Estado, que não se encerram com a troca de governos (Machado, Lima e Baptista, 2011).

No entanto, a opção da gestão municipal em investir prioritariamente em atendimentos de urgência e emergência apresentou incoerência com a aposta nacional de consolidar e qualificar a ESF como modelo de AB à saúde e como centro ordenador das RASs no SUS (Brasil, 2011a) - ainda mais que contrariava a Política Nacional de Promoção da Saúde (Brasil, 2010), pois objetivava promover a qualidade de vida e reduzir a vulnerabilidade e os riscos relacionados aos determinantes e condicionantes da saúde.

\section{A atuação dos profissionais da equipe de saúde}

Na pasta de processos judiciais do Conselho Municipal de Saúde, constatou-se que em agosto de 2009 houve uma denúncia do CMS ao Ministério Público Federal (MPF) que relatava irregularidades no âmbito da política nacional da ESF cometidas pela prefeitura estudada. Segundo tal denúncia, a prefeitura vinha recebendo recursos mensais do governo federal, porém sua utilização não estava de acordo com as diretrizes e exigências do programa. Os principais problemas relatados foram o descumprimento da carga horária mínima de quarenta horas semanais pelos profissionais com- 
ponentes da equipe mínima (enfermeiro, técnico em enfermagem e médico) e equipes incompletas.

Mediante a denúncia supracitada, o MPF constatou que não havia registro no Sistema de Informações da Atenção Básica (Siab), tampouco na produção de consultas pelos médicos da ESF. O gestor atuante naquele momento apresentou justificativas, mas o MPF manteve a planilha de cortes para a produção dessas equipes, recomendando o ressarcimento do montante recebido indevidamente ao Fundo Nacional de Saúde.

Sabe-se que permanecia ainda a questão dos profissionais médicos, que não completavam as vagas do concurso ou não assumiam quando chamados, o que deixava as equipes incompletas. O CMS denunciou ao Denasus a ausência de médicos para as 16 equipes de ESF. O Denasus, em auditoria realizada em março de 2012, constatou que mesmo com a realização do concurso público não houve candidatos inscritos em número suficiente para preencher as vagas disponíveis. A prefeitura propôs aumento salarial para os médicos, esperando assim regularizar, por meio de concurso público, as equipes de ESF e demais carências de médicos nas unidades básicas de saúde (UBSs).

Outro fator elencado pelos gestores foi o desconhecimento dos profissionais sobre a história e o sentido do SUS.

Muda governo, perde-se tudo! E existe um recomeço! (...) o que é que nós estamos errando? (...) não é nem de gestão, é que tipo de profissional, (...) eu não consigo ter atitude ou ter assegurado uma próxima gestão que vier, ou mostrar para a próxima gestão que existe esse trabalho, que já foi feito. Por que a gente não consegue avançar nisso? Então se o trabalhador não conhece a luta do SUS, a luta do que é fazer um acesso legal, uma equidade legal, uma integralidade do cuidado, (...) não saber de toda essa cadeia do SUS, não tem como nós avançarmos. (...) ainda falta muita atitude (Borboleta, $2^{\mathrm{a}}$ gestão).

Esse aspecto remeteu à postura dos trabalhadores de saúde, que por um lado justificou-se pela falta de política de pessoal e revelou um desinvestimento de consecutivas gestões, comprometendo o SUS (Trindade e Pires, 2013). Entretanto, na opinião de alguns entrevistados, também ocorreu a falta de organização ou postura política dos servidores municipais. É preciso reconhecer que essa atitude dos trabalhadores de saúde é uma força social e política que faz acontecer. $\mathrm{O}$ fato de não se posicionar, de não ter uma defesa do SUS, favorece que a cada governo tudo se reinicie; fragiliza a categoria e representa um retrocesso.

No caso do município estudado, o que garantiria maior governabilidade na saúde seria o empoderamento desses trabalhadores, que vai além da qualificação técnica - abrange principalmente a questão política e o compromisso ético com o projeto SUS. A mudança necessária aqui é usar a potência existente 
no grupo e transformar a realidade mediante uma ferramenta que envolva o trabalhador, pois apenas o sujeito implicado pode ser o sujeito da mudança (Franco, Chagas e Franco, 2012).

Desse modo, implicados e fortalecidos, os trabalhadores da ESF poderiam assumir uma perspectiva de oferta ampliada de ações na $A B$, o que favoreceria o atendimento das necessidades de saúde da população, complementada pela RAS. O horizonte que poderá ser vislumbrado está diretamente relacionado às várias forças políticas e ao momento histórico de cada local - e também às promessas e aos propósitos que o grupo de trabalhadores assumir (Giovanella, 2008).

Essas questões trazem à tona outra demanda, que é a forma como historicamente o servidor municipal de saúde foi tratado.

É importante reconhecer que o servidor público (...) de Santa Maria é muito maltratado pelo patrão. A desvalorização política da pasta da saúde tem produzido um efeito danoso sobre o setor, principalmente na total desvalorização do servidor público. E isso faz um efeito danoso, porque há total desapego com trabalho (Catina, $1^{a}$ gestão).

(...) primeira coisa: o município deve ter plano de cargo, carreira e salários (Mariana, $1^{\text {a }}$ e $2^{\text {a }}$ gestões).

Observa-se a importância de maior envolvimento por parte da gestão, de modo a efetivar um compromisso com direitos trabalhistas aos profissionais da saúde que desempenham atividades diárias com as comunidades. Então devem os gestores primar pela valorização salarial, uma vez que sem esse olhar há desmotivação e desestímulo por parte dos trabalhadores da saúde, que não recebem salários justos - o que implica a fragilização do vínculo profissional-usuário (Souza e Costa, 2010).

Além da importância salarial, é necessário que ocorra a valorização desse profissional como um todo, conforme propõe a PNH (Brasil, 2004b). A referida política apoia a "participação dos trabalhadores nos processos de discussão e decisão, reconhecendo, fortalecendo e valorizando seu compromisso com o processo de produção de saúde e seu crescimento profissional" (Brasil, 2004b, p. 11).

Uma proposta que facilita esses diálogos, aproxima e integra os diferentes segmentos e amplia as discussões são os colegiados de gestão nos territórios. A gestão colegiada favorece a construção de um espaço na organização municipal que incentiva os servidores “a agirem tecnicamente como facilitadores na criação de alternativas de ações inovadoras, visando à melhoria na qualidade do serviço prestado" (Duarte Silva et al., 2012, p. 342-343). 
No decorrer da implementação do SUS, houve muitos avanços e permanentes desafios, o que tem exigido dos gestores, trabalhadores e usuários do sistema o movimento de repensar e reorganizar suas práticas, as relações e as ações empregadas na sua construção. A implantação da ESF no município estudado sinalizou uma profunda e complexa relação com a história do SUS. Também a partir de tal trajetória é importante analisar e sinalizar que essa história certamente acarretou importantes reflexos na expansão da cobertura da ESF no município, considerando que praticamente permaneceu a mesma por todos esses anos.

Assim, analisar o processo de implantação da ESF no município de Santa Maria remete à necessidade de aprender e repensar as próprias configurações do SUS. Acredita-se que deixar a história falar é uma forma de utilizá-la para que não se repitam equívocos e apostas que já se sabe serem pouco eficientes e eficazes na gestão municipal, considerando a complexidade da construção local de saúde como "campo privilegiado do conhecimento emancipatório" (Santos, 2009, p. 81).

\section{Considerações finais}

É importante afirmar que o processo da ESF do município analisado revelou aspectos ricos de aprendizado. A questão da gestão do trabalho e as escolhas da gestão da saúde apareceram como fragilidades da ESF e se mostraram como seus principais obstáculos. Apreendeu-se que as escolhas da gestão ou a proposta de governo foram os disparadores para a melhoria ou degradação do SUS. Conhecer os propósitos do SUS é condição para sua implementação, identificando sua complexidade com as numerosas interfaces que precisam ser abordadas na gestão municipal.

Constatou-se que a ESF se iniciou no município de forma vivaz, com uma gestão participativa, envolvendo CMS, poder legislativo, comunidade, universidade e trabalhadores. Ao responder à questão da falta de continuidade, alguns elementos foram destacados, como a forma de contratação das equipes, a não instituição dos colegiados gestores e a dicotomia entre ESF e AB. Tais escolhas comprovaram que a cada gestão o processo precisou ser reiniciado, principalmente pela instabilidade e rotatividade dos trabalhadores - o que não possibilitou a construção de vínculo com as comunidades.

Assim, a ESF sofreu com o impacto da demissão em massa exigido pelo MPT, que somado às novas escolhas da gestão municipal foi determinante para que as equipes atuassem de forma desprotegida, seja na questão trabalhista, seja no acompanhamento das práticas de saúde. O município permaneceu por longo período com trabalhadores da ESF sem o acompanhamento 
da gestão e sem educação permanente, enquanto a gestão municipal, de forma excludente, fortalecia o atendimento de urgência-emergência. A pesquisa revelou as implicações das escolhas da gestão na fragmentação do sistema, comprometendo a integralidade da atenção, uma defesa cara para o SUS.

Constatou-se na pesquisa a desvalorização da pasta da saúde pelos sucessivos governos, bem como uma ausência de postura consciente de defesa do SUS. A gestão municipal no trabalho em saúde precisa reconhecer que os sujeitos têm desejos, interesses, intencionalidades individuais, histórias, rede de relações, escolhem seus partidos políticos. Enfim, para compor um grande pacto, o SUS precisaria se tornar um projeto comum a todos.

Revelou-se aqui a complexidade que é fazer gestão municipal do SUS e que o fato de municípios de médio porte - como o caso do município estudado - terem capacidade instalada satisfatória na média e alta densidade tecnológica não os dispensa de sedimentarem a AB para efetivar a RAS com integralidade.

A experiência contada neste artigo resumiu uma pesquisa que se empenhou em descrevê-la ouvindo gestores e analisando documentos do CMS. Para ampliar o elenco de aspectos contidos nesse processo, os conselheiros municipais de saúde, usuários e trabalhadores também poderiam ser entrevistados, o que revela um limite do estudo.

\section{Colaboradores}

Maria Denise Schimith realizou a pesquisa de campo e participou de todas as etapas de produção do artigo; Ana Cristina Passarella Brêtas e Bruna Sodré Simon participaram na orientação da pesquisa; Dyan Jamilles Teixeira Brum e Gabriela Fávero Alberti auxiliaram na coleta de dados e na produção final do texto; Maria de Lourdes Denardin Budó e Taís Falcão Gomes participaram na produção final do texto. Não há, por parte dos autores, conflito de interesses com relação à pesquisa. 
Resumen El estudio tuvo como meta comprender el proceso de implantación y seguimiento de la Estrategia Salud de la Familia, en un municipio del estado de Río Grande do Sul, Brasil, utilizando como metodología la investigación cualitativa. Se entrevistaron 16 gestores y se analizaron fuentes documentales en el período de agosto de 2011 a mayor de 2012. El material se sometió a la propuesta operativa de análisis. Ser constató que la primera gestión de la estrategia desencadenó un proceso efervescente para transformar una realidad considerada fragmentada e insuficiente, optando por la tercerización en la contratación de los trabajadores, participación de la comunidad y educación permanente. La segunda gestión optó por fortalecer las unidades de primeros socorros, sin la participación del control social. Aparecieron como fragilidades de la Estrategia la gestión del trabajo y las selecciones de la gestión municipal. La reestructuración de la atención básica, objetivo de la Estrategia, fue postergada. Como conclusión, se identificó la complejidad de la gestión municipal del Sistema Único de Salud y sedimentar la atención básica como puerta preferencial de los ciudadanos.

Palabras clave gestión en salud; recursos humanos en salud; Estrategia Salud de la Familia; Sistema Único de Salud.

\section{Notas}

1 Universidade Federal de Santa Maria, Departamento de Enfermagem, Santa Maria, Rio Grande do Sul, Brasil.

$<$ ma.denise2011@gmail.com>

Correspondência: Universidade Federal de Santa Maria, Departamento de Enfermagem, Avenida Roraima, 1.000, Camobi, CEP 97105-900, Santa Maria, Rio Grande do Sul, Brasil.

2 Universidade Federal de São Paulo, São Paulo, SP, Brasil.

<acpbretas@ymail.com>

3 Universidade Federal do Pampa, Bagé, Rio Grande do Sul, Brasil.

$<$ enf.brusimon@gmail.com>

4 Universidade Federal de Santa Maria, Santa Maria, Rio Grande do Sul, Brasil.

$<$ jamillesenf@gmail.com>

5 Universidade Federal do Rio Grande do Sul, Porto Alegre, Rio Grande do Sul, Brasil. $<$ g_falberti@hotmail.com>

6 Universidade Federal de Santa Maria, Santa Maria, Rio Grande do Sul, Brasil.

$<$ lourdesdenardin@gmail.com>

7 Universidade Federal de Santa Maria, Programa de Residência Multiprofissional, Santa Maria, Rio Grande do Sul, Brasil.

$<$ taissfg@gmail.com>

8 Texto inédito resultante da pesquisa Processo de implantação e implementação da Estratégia Saúde da Família no município de Santa Maria, Rio Grande do Sul, Brasil, 
de Maria Denise Schimith e colaboradores, Santa Maria, Rio Grande do Sul, janeiro de 2011, financiada pelo Fundo de Incentivo à Pesquisa (Fipe) da Universidade Federal de Santa Maria, vigência 2010-2014.

\section{Referências}

BRASIL. Ministério da Saúde. Conselho Nacional de Saúde. Resolução n. 196, de 10 de outubro de 1996. Dispõe sobre as diretrizes e normas regulamentadoras de pesquisa envolvendo seres humanos. Diário Oficial da União, Brasília, DF, 10 nov. 1996. Disponível em: <http://conselho.saude.gov.br/web_ comissoes/conep/aquivos/resolucoes/23_ out_versao_final_196_ENCEP2012.pdf > . Acesso em: 20 jan. 2011.

BRASIL. Ministério da Saúde. Assessoria de Comunicação do Ministério. Indicadores de monitoramento da implementação do PSF em grandes centros urbanos. Brasília: Ministério da Saúde, 2002. Disponível em: <http://dab. saude.gov.br/docs/geral/indicadores_psf_ centros.pdf $>$. Acesso em: 10 jan. 2011.

BRASIL. Ministério da Saúde. Portaria n. 626/GM, de 8 de abril de 2004a. Cria Comissão Especial para elaborar as Diretrizes do Plano de Carreira, Cargos e Salários do âmbito do SUS. Diário Oficial da União, Brasília, 8 abr. 2004. Disponível em: <http:// ufesemus.files. wordpress.com/2010/10/ portaria-nc2ba-626-gm-de-8-de-abril-de2004-ms.pdf $>$. Acesso em: 11 out. 2016.

BRASIL. Ministério da Saúde. Secretaria Executiva. Núcleo Técnico da Política Nacional de Humanização. HumanizaSUS: Política Nacional de Humanização - a humanização como eixo norteador das práticas de atenção e gestão em todas as instâncias do SUS. Brasília: Ministério da Saúde, 2004b. Disponível em: <http://bvsms.saude.gov.br/bvs/ publicacoes/humanizasus_2004.pdf $>$. Acesso em: 11 out. 2016.
BRASIL. Pacto pela Saúde 2006: consolidação do SUS e aprova as diretrizes operacionais do referido pacto. Brasília: Ministério da Saúde, 2006. Disponível em: <http:// bvsms.saude.gov.br/bvs/saudelegis/gm/ 2006/prt0399_22_02_2006.html>. Acesso em: 11 out. 2016.

BRASIL. Portaria n. 1.996, de 20 de agosto de 2007. Dispõe sobre as diretrizes para a implementação da Política Nacional de Educação Permanente em Saúde. Diário Oficial [da] República Federativa do Brasil, Poder Executivo, Brasília, 22 ago. 2007. Disponível em: <http://www.saude.mt.gov.br/upload/ legislacao/1996-[2968-120110-SES-MT].pdf> . Acesso em: 11 out. 2016.

BRASIL. Ministério da Saúde. Secretaria de Vigilância em Saúde. Secretaria de Atenção à Saúde. Política Nacional de Promoção da Saúde. 3. ed. Brasília: Ministério da Saúde, 2010. Disponível em: <http://bvsms.saude. gov.br/bvs/publicacoes/politica_nacional_ promocao_saude_3ed.pdf $>$. Acesso em: 11 out. 2016.

BRASIL. Ministério da Saúde. Portaria n. 2.488, de 21 de outubro de 2011: aprova a Política Nacional de Atenção Básica, estabelecendo a revisão de diretrizes e normas para a organização da Atenção Básica, para a Estratégia Saúde da Família (ESF) e o Programa de Agentes Comunitários (Pacs). Brasília: Ministério da Saúde, 201la. Diário Oficial da União, Brasília, 21 nov. 2011 a. Disponível em: <http://bvsms.saude.gov. br/bvs/saudelegis/gm/2011/prt2488_21_ 10_2011.html>. Acesso em: 11 out. 2016. 
BRASIL. Ministério da Saúde. Secretaria de Atenção à Saúde. Departamento de Atenção Básica. Acolhimento à demanda espontânea. Brasília: Ministério da Saúde, 2011b. Disponível em: <http://189.28.128.100/dab/docs/ publicacoes/geral/miolo_CAP_28.pdf $>$. Acesso em: 11 out. 2016 .

BRASIL. Ministério da Saúde. Departamento da Atenção Básica. Projeto de Expansão e Consolidação Saúde da Família. Brasília: Ministério da Saúde, 2011c. Disponível em: $<$ http://bvsms.saude.gov.br/bvs/publicacoes/ PROESF.pdf>. Acesso em: 10 jan. 2011.

BRASIL. Ministério da Saúde. Departamento da Atenção Básica. Sala de Apoio à Gestão Estratégica. Saúde mais perto de você: equipes da saúde da família. 2014. Disponível em: $<$ http://dab.saude.gov.br/portaldab/smp_ o_que_e.php >. Acesso em: 15 jul. 2014.

DUARTE SILVA, Cristina M. et al. Implantação do colegiado de gestão: relato de experiência do Território Três, Volta Redonda. In: PINTO, Suely; FRANCO, Túlio B.; MAGALHÃES, Marta G. (orgs.). Tecendo redes: os planos da educação, cuidado e gestão na construção do SUS - a experiência de Volta Redonda-RJ. São Paulo: Hucitec, 2012. p. 339-348.

FERNANDES, Janielle S. et al. A relação dos aspectos profissionais na qualidade de vida dos enfermeiros das equipes saúde da família. Revista da Escola de Enfermagem da USP [online], São Paulo, v. 46, n. 2, p. 404-412, 2012. Disponível em: <www.scielo.br/scielo. php?script $=$ sci_arttext $\&$ pid $=$ S008062342012000200019>. Acesso em: 11 out. 2016.

FRANCO, Túlio B.; CHAGAS, Rafael C.; FRANCO, Camila M. Educação permanente como prática. In: PINTO, Suely; FRANCO, Túlio B.; MAGALHÃES, Marta G. (orgs.). Tecendo redes: os planos da educação, cuidado e gestão na construção do SUS - a experiência de Volta Redonda-RJ. São Paulo: Hucitec, 2012. p. 45-62.

GIOVANELLA, Ligia. Atenção primária à saúde seletiva ou abrangente? Cadernos de
Saúde Pública, Rio de Janeiro, v. 24, supl. 1, p. s21-s23, 2008.

MACÊDO, Neuza B.; ALBUQUERQUE, Paulleti C.; MEDEIROS, Kátia R. O desafio da implementação da educação permanente na gestão da educação na saúde. Trabalho, Educação e Saúde, Rio de Janeiro, v. 12, n. 2, p. 379-401, maio-ago. 2014.

MACHADO, Cristiani V.; LIMA, Luciana D.; BAPTISTA, Tatiana W. F. Princípios organizativos e instâncias de gestão do SUS. In: OLIVEIRA, Roberta G.; GRABOIS, Victor; MENDES JR., Walter V. (orgs.). Qualificação dos gestores do SUS. 2. ed. Rio de Janeiro: Editora Fiocruz, 2011.p. 47-72.

MEDEIROS, Cássia R. G. et al. A rotatividade de enfermeiros e médicos: um impasse na implementação da Estratégia Saúde da Família. Ciência \& Saúde Coletiva [online], Rio de Janeiro, v. 15, supl. 1, p. 1.521-1.531, 2010. Disponível em: <www.scielo.br/pdf/ csc/v15s1/064.pdf>. Acesso em: 11 out. 2016.

MENDES, Eugênio V. O cuidado das condições crônicas na atenção primária à saúde: o imperativo da consolidação da Estratégia Saúde da Família. Brasília: Organização Pan-Americana da Saúde, 2012.

MINAYO, Maria C. S. O desafio do conhecimento: pesquisa qualitativa em saúde. 13 ed. São Paulo: Hucitec, 2013.

ROCHA, Paulo M. et al. Avaliação do Programa Saúde da Família em municípios do Nordeste brasileiro: velhos e novos desafios. Cadernos de Saúde Pública, Rio de Janeiro, v. 24, supl. 1, p. s69-s78, 2008. Disponível em: <www.scielo.br/pdf/csp/v24s1/12.pdf>. Acesso em: 13 out. 2016.

ROLIM, Leonardo B.; CRUZ, Rachel S. B. L. C.; SAMPAIO, Karla J. A. J. Participação popular e o controle social como diretriz do SUS: uma revisão narrativa. Saúde em Debate, Rio de Janeiro, v. 37, n. 96, p. 139-147, jan.-mar. 2013.

SANTOS, Boaventura S. Para um novo senso comum: a ciência, o direito e a política na 
transição paradigmática. 7. ed. São Paulo: Cortez, 2009.

SouZA, Georgia C. A.; CosTA, Iris C. C. O SUS nos seus 20 anos: reflexões num contexto de mudanças. Saúde e Sociedade, São Paulo, v. 19, n. 3, p. 509-517, 2010.

SOUZA, Maria C. M. R. et al. Municipalização em saúde: avanços, desafios e atuação do enfermeiro. Revista de Enfermagem do Centro Oeste Mineiro, São João del Rei, v. 1, n. 1, p. 112-120, jan.-mar. 2011.

STARFIELD, Bárbara. Atenção primária: equilíbrio entre necessidades de saúde, serviços e tecnologia. Brasília: Unesco, Ministério da Saúde, 2002.
TRINDADE, Letícia L.; PIRES, Denise E. P. Implicações dos modelos assistenciais da atenção básica nas cargas de trabalho dos profissionais de saúde. Texto \& Contexto Enfermagem [online], Florianópolis, v. 22, n. 1, p. 36-42, 2013. Disponível em: <www.scielo. br/pdf/tce/v22nl/pt_05.pdf >. Acesso em: 13 out. 2016.

VICTORA, Ceres G.; KNAUTH, Daniela R.; HASSEN, Maria N. A. Pesquisa qualitativa em saúde: uma introdução ao tema. Porto Alegre: Tomo Editorial, 2000.

Recebido em 30/09/2014

Aprovado em 11/06/2015 